\title{
Research on Processing and Making Technology of Wooden Crafts
}

\author{
Zhen Bai, Qiang Feng \\ Northwestern polytechnical university of Ming College, Shaanxi, Xi'an, \\ 710124, China
}

\begin{abstract}
Wooden handicrafts are more and more loved by the people in the contemporary, and are introduced into foreign markets as a representative of Chinese culture, caused a big sensation and became the material carrier conveying the Chinese traditional culture. In modern society, exploring and analyzing its processing and production process is conducive to show its processing and production process, and put forward the positive significance of wood products processing and production by the machinery and equipment in current situation.

Keywords: wood crafts; handmade; mechanical processing
\end{abstract}

\section{Introduction}

Since ancient times, China has the production of handicrafts. In the vast ancient China, people live full of imagination and creativity, they are in the art of cell infiltration, have to find different materials, and constantly develop production tools and techniques to produce batch after batch of highly ornamental handicrafts, Part of the handicrafts remain practical and ornamental unity. Wooden handicrafts is also a branch of the production of handicrafts in China, its production process, contains the cultural connotation has been circulating in China for thousands of years, affecting generation after generation. Modern society, science and technology is extremely developed, a variety of handicrafts increasing the number has become Chinese consumer market is very common objects. 


\section{The wooden handicrafts}

\subsection{The wood products}

The meaning of wooden handicrafts can be understood from its literal sense. First of all, that is "handicrafts." Handicraft is through manual or mechanical processing, will be a certain material into an aesthetic and ornamental item, is a group of artistic value of the items in general, including pottery, wood carvings, porcelain and folk crafts and other types. Therefore, wood crafts, is a kind of handicrafts, included in the category of crafts, and thus also has the characteristics of handicrafts, aesthetic and ornamental; secondly, "wood." "Crafts" determines the ownership of wood products or areas, and "wood" is determined by its material. Material refers to the crafts themselves raw materials, such as jade Ruyi, jade itself material; collection in the Taipei Palace Museum "jade cabbage" material for half gray, half green jade. Wooden handicraft material, compared to "wood." Comprehensive two aspects, the simple meaning of wood crafts can be drawn: wood for the material with the artistic value of the items.

\subsection{The cultural significance of wood products}

Wooden handicraft is our unique style of art, with excellent aesthetic characteristics and ornamental. And wood for the production of handicrafts, in our history is extremely long, in the Hemudu cultural sites and they found wood carving fish that more than 7000 years ago, the ancient people of China began to produce wood crafts. After thousands of people continue to its material selection, processing and production process of the rich and development of Chinese current wooden craft production process has been quite perfect. At present, with the wooden craft out of the domestic market, to enter the international market, in the international context of a larger response, foreign friends have marveled at its exquisite workmanship, beautiful shape, wooden handicrafts has become Chinese traditional culture and convey the essence of our excellent traditional culture.

\section{The development status quo of wood products}

At present, Chinese rapid economic development, wooden handicrafts as one of the carriers of traditional culture, but also the representative of Chinese handicraft market, but also with the passage of time there have been gratifying changes. Mainly in the following three points:

\subsection{The Number of dramatic increases}

First of all, Chinese market in the number of wooden handicrafts surge. In ancient times, due to the constraints of historical and cultural conditions, Chinese low level of scientific and technological development, it is also very limited 
understanding. The background of the times, wooden handicrafts basically by the relevant staff of purely hand-made, and the production and processing tools are relatively simple; with wooden craft production process is more complex. Therefore, leading to the production of wooden crafts a long time, mature handicraft production is low. Modern conditions, science and technology and machinery and equipment manufacturing process for the production of wood products processing and production of the corresponding machinery. Through mechanical equipment for wood products processing and production, to ensure the accuracy of the production, but also improve the production speed, making a large number of wood products in the market.

\subsection{The tendency of industrialization}

Industrialization is a concept of economics, with market-oriented, industry advantages, scale of operation and professional division of labour, with the industry, "leading" driven, supporting services and market-oriented operation. At present, with the increase in market demand, the production and processing of wood products has gradually become an industry, which derived from an industrial chain, including the production of wood crafts and processing, market circulation and sales.

\subsection{Improve the economic efficiency}

With the production of wooden handicrafts and the industrialization of the number of accelerated, its access to economic efficiency is an inevitable trend. At present, the production of wooden crafts and processing can be divided into three general: pure hand-made and processing; purely mechanical production and processing and semi-hand semi-mechanical production and processing. Handmade wooden handicrafts, there is still a long production time, consumption of energy and other characteristics. And because of the wooden crafts are often very good ornamental, and by the community's unanimous recognition and praise, people increased its demand, naturally led to its economic growth.

\section{The introduction of wooden handicraft processing and production process}

On the million mentioned in the current wooden handicraft processing and production process can be divided into three kinds, pure handmade, purely mechanical production and semi-hand semi-mechanical production. Three ways have their advantages, while the production process and there are differences in the three kinds of production process in this simple introduction. 


\subsection{Purely manual processing and production process}

Hand-processing and production of wood products, requires producers with excellent professional standards and a wealth of experience in the production. Chinese four major wood carvings - Fujian wood carvings, the most representative handicrafts for the longan wood, made of longan wood. Longan wood solid material, wood is more detailed, the trunk, root intertwined, with a variety of posture, suitable as a wood carving raw materials. Its production process is generally required to go through a billet, repair light, polishing, dyeing, painting, waxing and other processes. Engraving small items, the material is usually placed on the wooden pier above the foot clip to the rod under the knife waving; large items are required to the rough, cut out the shape of the work, the above process is called rough Billet. After the rough billet is finished, need to carry on the carving, forms the thin billet, in this process to the rough billet shape carries on the minute adjustment. Repairing light is mainly on the basis of thin billet, the use of thin knife to its rough blanks and fine blanks produced by the process of leaving the knife marks, chisel scale removal, the wood surface smooth and meticulous..

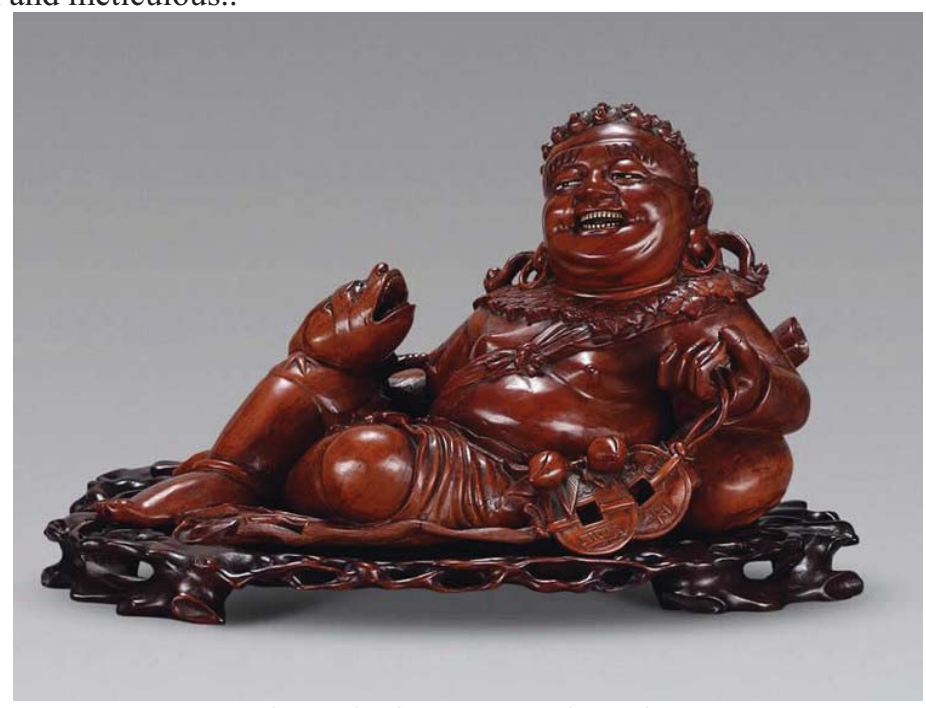

Fig.1 The longan wood carving

\subsection{Purely mechanical processing and production process}

Wooden handicraft processing equipment according to the specific design of handicrafts, can be used lathe, milling machine, CNC machine tools, wood line machine, peeling machine, and for the planing of the belt drive fine machine, peeling machine and $\mathrm{CNC}$ machine tools and other types. The specific processing method is mainly to clean the decontamination process after the completion of the raw material clamping fixture in the processing equipment, and then knife, 
drill, cut and other mechanical processing means of the wood material processing, the following A brief introduction of lathe production of wood crafts process.

Lathe mainly through turning tools on the rotation of the object turning, according to the specific processing and production requirements, but also with drill, reamer and so on. The tool in the lathe according to the specific requirements of wood crafts vary; such as in the processing of a pot-shaped wooden handicrafts, the first need to face its turning, processing of the end of the craft (in general, refers to the cylindrical objects at both ends of the plane), Can be fixed in the lathe first, after the outer turning tool for its end surface processing; after the adoption of forming lathe processing craft molding surface. The operation is simple and convenient; the pot wood handicrafts in the port requirements There are trenches, grooves can be used to groove, the method as above; arc file is mainly used for the shape of the object on the arc, the case of pot-shaped wooden handicrafts, with a circular arc, so round The arc file is machined to ensure that it has an arc on its appearance. After the end face, molding surface, groove, arc and a series of processes, the shape of the potshaped wooden handicrafts have been formed, so just through the grinding wheel grinding the surface of the craft, and finally fine sandpaper grinding.

\subsection{The combination of manual and mechanical processing and production}

In addition to purely hand-made wooden handicrafts and purely mechanical production of wooden crafts, there is also semi-hand semi-mechanical processing and production of wood products, the production process can be seen as simple hand-made and mechanical processing complex. In accordance with the current science and technology and the development of machinery and equipment, wood products processing can basically be completed by mechanical processing. However, there are some limitations of mechanical processing, such as the choice of raw materials, crafts, machinery without thinking ability, and human beings can give full play to their subjective initiative, based on their understanding of wood and crafts specific requirements, select wood. Again, the wood cleaning and decontamination processes also need to be carried out by hand, the use of mechanical cleaning wood, easy to cause unnecessary damage to the wood, the impact of the subsequent processing and production processes. At the same time, machinery and equipment also need to spend a certain amount of cost, especially CNC machine tools, high cost, for most of the wood craft makers are not a small burden. Therefore, at present, many wood crafts makers are more inclined to semi-hand semi-mechanical production of wood products in the choice of wood, cleaning, decontamination process by hand to complete; rough blanks, rough grinding process through mechanical completion, after completion, according to the actual requirements of crafts increase or decrease processes. Semi-manual semi-mechanical processing and production of wooden handicrafts, can take full advantage of people's initiative, imagination and creativity, based on the integrated mechanical equipment, high precision, free from time, space, and energy constraints of the organic combination. 


\section{Conclusion}

Chinese wood products originator has a long history, the wooden handicraft processing and production techniques continue to progress and improve in the inheritance and development. At present, with the progress and development of science and technology, a wide range of machinery and equipment are manufactured, attracting a large number of wood industry producers' attention, which produced three tendencies in the production of wooden handicrafts pure handmade, purely mechanical and semi-manual semi-mechanical. Regardless of the way in which the wood handicraft processing and production, one thing can not be ignored, that is the mechanical equipment brings change and innovation to wood processing and production to adapt to the rhythm of modern society and trends.

\section{Acknowledgements}

The research work was supported by College project: Research on the development and innovation of wooden crafts.

\section{References}

[1] Liu Yan. Study on the Industrialization of Peach Wood Carving in Feicheng from the Perspective of Intangible Cultural Heritage Journal of Taishan University, 55(12), pp.68-70, 2014

[2] Zheng Hai, Wang Jing, Lin Qiao, Zi Han, Wang Jia, Yang Bo, Guang Kui.Traditional Ethnic Handicrafts in Yunnan: Puzzle Behind Beauty, 8(5), pp.87- 91, 2013

[3] Bian Xuesong. Study on the Processing and Making Technology of Wooden Crafts; Modern Economic Information; 12(10), pp. 18- 20, 2015 